Vol. 4, no 1. 2019, Julho de 2019.

\title{
A importância das aulas de campo para o aprendizado de Geografia e sua utilização na Escola Miguel Calado Borba, Angelim - PE
}

\author{
The importance of field lessons for the learning of Geography and its use in the Miguel \\ Calado Borba School, Angelim - PE
}

\author{
José Leandro Alves VIANA
}

\begin{abstract}
Mestrando em Geografia pela Universidade Federal de Alagoas.
E-mail: leo-geografia@hotmail.com
\end{abstract}

\begin{abstract}
Resumo
As aulas de campo de Geografia são uma das temáticas que encontram-se em ênfase nos debates da educação contemporânea, principalmente quando integradas às questões relacionadas ao ensinoaprendizagem. Assim sendo este trabalho trata da importância das aulas de campo para o aprendizado de Geografia e sua utilização na Escola Miguel Calado Borda do município de Angelim - PE, esta pesquisa objetiva analisar o processo de influência que as aulas de campo possuem no aprendizado dos alunos. Para atender a este objetivo, a metodologia utilizada foi baseada em estudos teóricos referenciados que mostram a importância desta temática também como quebra dos velhos paradigmas que fundamentam as práticas pedagógicas, tendo por base as obras dos autores Cordeiro e Oliveira (2011), Fontinha (2017), Júnior e Gonçalves (2012), Pisetta (2013), Silva e Júnior (2016). Do mesmo modo que foram realizadas aulas de campo com as turmas $6^{\circ} \mathrm{A}, \mathrm{B}$ e D de ensino fundamental II da Escola Miguel Calado Borba e posteriormente foram avaliados os conhecimentos dos alunos a respeito das temáticas abordadas nas aulas de campo que versaram a respeito de conteúdos de abordagem geográfica como solo, vegetação, clima, relevo e o espaço geográfico. O estudo concluiu que há um quadro favorável quanto à aplicação das aulas de campo em Geografia, como suporte para o aprendizado dos conteúdos e conhecimento do espaço geográfico por parte do alunado, visto que é possível perceber que esta metodologia possui eficácia em sua utilização e mostra-se proveitosa na melhoria dos processos de aprendizagem dos discentes.
\end{abstract}

Palavras-chave: Ensino-aprendizagem. Influência. Conhecimentos. Eficácia.

\begin{abstract}
The Geography field classes are one of the main ones that are in practice in the debates of contemporary education, especially when integrated to the issues related to teaching-learning. Thus, this work deals with the importance of the field lessons for the learning of Geography and its use in the Miguel Calado Borda School in the city of Angelim - PE, this research get the object the analyze and influence that the field classes have in the students' learning. To achieve the goal, the methodology used was based on theoretical studies that present the importance of this logic as the breakdown of the old paradigms that are based as pedagogical practices, based on the works of the authors Cordeiro and Oliveira (2011), Fontinha (2017), Júnior and Gonçalves (2012), Pisetta (2013), Silva and Júnior (2016). In the same way that
\end{abstract}


the field classes with classes $6^{\circ} \mathrm{A}, \mathrm{B}$ and D of elementary school II of the Miguel Calado Borba School and others were evaluated in order to have access to the thematic classes addressed in the field lessons that deal with respect of content geographic approach such like soil, vegetation, climate, relief and geographic space. The study concluded that there is a favorable framework for the application of the field lessons in Geography, like a support for the learning of contents and knowledge of the geographic space on the part of the student, showed profitable in improving the learning processes of the students.

Key words: Teaching-learning. Influence. Knowledge. Effectiveness.

\section{Introdução}

Há tempos, a relação dos seres humanos na organização do espaço é objeto de análise dos que se preocupam com a construção do mesmo, uma vez que, como objeto mutável, o espaço é fruto de um processo de transformação proporcionado pelos seres que o vivenciam. Nesta perspectiva, o presente trabalho visa investigar a influência que as aulas de campo da disciplina Geografia possuem no aprendizado dos alunos com relação aos conteúdos abordados em sala, assim como do conhecimento do espaço geográfico como ambiente de vivência humana e realização de nossas atividades cotidianas.

Ultimamente notamos a publicação de trabalhos e pesquisas propondo debates a respeito das aulas de campo em diversas disciplinas escolares e especialmente em Geografia, tendo em vista esta disciplina está associada ao conhecimento do espaço em que vivemos, para que nele possamos intervir de forma consciente, coletiva e com vistas à promoção de um desenvolvimento humano e social, desta forma, procuramos entender a importância das aulas de campo para o aprendizado discente, refletindo à luz das contribuições de uma teoria científica e social em torno desta ferramenta de ensino.

Desta maneira, a concepção deste trabalho está associada à nossa busca e interesse em refletir de forma sistemática sobre todo esse processo que vem promovendo reflexões de diversos profissionais, tendo em vista que convenciona-se que promover aulas práticas e diferenciadas é importante para dinamizar o processo de ensino-aprendizagem, fomentando o bom desempenho do trabalho docente e consequentemente o aprendizado discente.

Vivemos em um modelo de sociedade que se transforma a cada dia e muitas vezes de maneira muito rápida, e com o advento da globalização o conhecimento está mais difundido e consequentemente mais perto de todos. Os avanços do mundo globalizado incentivaram transformações na sociedade e estas mudanças permeiam diretamente a prática pedagógica e a formulação de novos saberes. A evolução das práticas pedagógica vem associada às novas formas de trabalho, novos métodos, técnicas e ferramentas que atribuem um caráter específico a cada disciplina escolar, isso é o que acontece no momento com a disciplina Geografia.

Desta forma, a aulas de campo pode ser entendidas como um conjunto de práticas educativas que auxiliam na construção de cidadãos comprometidos e cientes de seu papel em sociedade, a partir do conhecimento e atuação no espaço geográfico. Assim sendo, as aulas de campo se utilizadas corretamente como prática pedagógica na disciplina Geografia trazem contribuições imprescindíveis para todos de forma direta a partir da atuação dos discentes como cidadãos mais conscientes, até porque, uma de suas funções principais é trabalhar diretamente com o aluno que é um ser em formação, o seu espaço de vivência, contribuindo assim em seu desenvolvimento como ser humano.

As aulas de campo vem trazendo contribuições não só para a educação, mas também passam a fazer parte do cotidiano de diversos grupos humanos, tendo em vista que as práticas 
educativas refletem nos demais aspectos da vida em sociedade. Mediante este contexto, os profissionais de diversas áreas se veem incentivados a promover reflexões sobre a sociedade, a educação e a prática na formação de seus alunos.

A realidade não só do aluno, mas do próprio contexto histórico precisa ser compreendida de forma ampla para que consigamos construir uma educação realista, próspera e próxima da sociedade a qual atende. O compromisso das aulas de campo em Geografia é com a formação constante de estudantes mais conscientes no que diz respeito a atitudes, emoções, sentimentos e valores, abrindo margem para debates e investigações, aprimoramento as perspectivas atuais, sua função é essencial para a construção de conhecimentos, habilidades e da ação social por parte de seu público, os discentes.

A educação atual requer um desenvolvimento da prática pedagógica voltada para as mudanças, e uma fundamentação teórica capaz de atender aos novos educandos. Nessa busca por novas formas de fazer educação diferente, de modo a envolver o aluno no processo de ensino-aprendizagem, favorecendo sua participação, é possível pensar que a utilização de novos recursos metodológicos torna-se um instrumental que contribui também para a aprendizagem, neste contexto entra as aulas de campo como integram métodos de trabalho dos docentes ampliando as possibilidades do alcance dos objetivos principais da educação.

Mediante a análise que realizamos, concluímos que as aulas de campo em Geografia são muito importantes para o alcance do aprendizado e da conscientização do espaço de vivência dos alunos, já que existe uma série de contribuições que esta ferramenta promove a partir de métodos e técnicas específicas da disciplina Geografia.

\section{Métodos}

As aulas de campo no contexto escolar são uma temática que está em ênfase nos debates da educação. Visando entender o papel desta metodologia nos moldes educacionais, este estudo objetiva analisar a importância das aulas de campo para o aprendizado dos estudantes das turmas do $6^{\circ}$ ANO A, B e D do ensino fundamental II da Escola Miguel Calado Borba do município de Angelim - PE.

Maior instituição escolar do município de Angelim e em atividade desde 1977, a Escola Miguel Calado Borba situa-se à Rua Barão do Rio Branco s/n, Centro, funciona nos turnos da manhã, tarde e noite e possui atualmente 10 turmas de Ensino Infantil, 20 de Ensino Fundamental I, 19 de Ensino Fundamental II e 8 de EJA Fundamental.

Figura 1 - Escola Miguel Calado Borba 
Vol. 4, no 1. 2019, Julho de 2019.

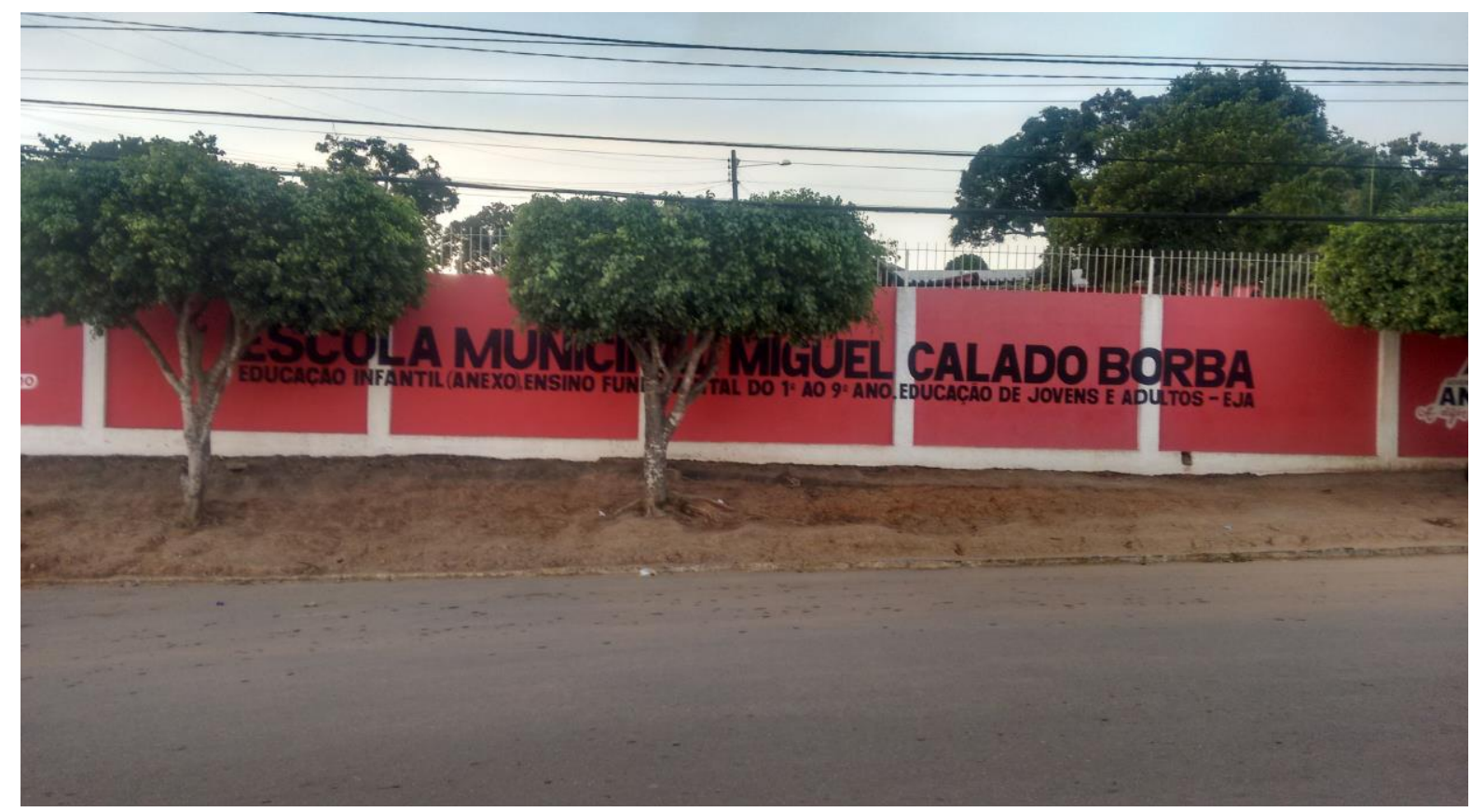

Fonte: Arquivo do autor

A escolha pelo tema justifica-se a partir de nossas inquietações a respeito da importância das aulas de campo no contexto escolar atual e como elas podem ser utilizadas de uma forma geral para a ampliação e alcance dos objetivos educacionais. Dessa forma, analisar o papel e as contribuições das aulas de campo para o aprendizado dos conteúdos escolares da disciplina Geografia é objeto desta pesquisa.

Com o objetivo de atingir as propostas do presente trabalho foi adotada uma pesquisa qualitativa a partir de um levantamento detalhado do referencial teórico contemplando artigos, sites da internet e publicações que deram um importante embasamento ao trabalho realizado. A pesquisa qualitativa bibliográfica é constantemente utilizada devido à riqueza das informações que podemos resgatar, contribuindo para a fundamentação de várias temáticas utilizadas nas ciências humanas e sociais.

O levantamento bibliográfico proposto para o desenvolvimento desta pesquisa é baseado em concepções teóricas e trabalhos de autores consagrados que serviram de suporte para a articulação e fundamentação de nosso trabalho como as obras de Cordeiro e Oliveira (2011), Fontinha (2017), Júnior e Gonçalves (2012), Pisetta (2013), Silva e Júnior (2016), dentre outros, os quais mostraram a importância e contribuições das aulas de campo para o aprendizado da disciplina Geografia.

Como prática de pesquisa realizamos aulas de campo no município de Angelim - PE, nos arredores do povoado Quatro Bocas, localidade já utilizada em diversos outros momentos para a promoção de aulas de campo com turmas daquela localidade, tendo em vista que os sítios, fazendas e terrenos em suas redondezas são espaços rurais de belas paisagens, neste caso agora em especial, buscamos identificar a influência das aulas de campo para o aprendizado dos discentes, promovendo assim aulas diferenciadas que auxiliem e venham a contribuir para o processo de ensino-aprendizagem dos alunos da escola mencionada.

A prática de campo foi realizada no dia 14 de setembro de 2018 com suporte da direção e coordenação da escola, para o trabalho de campo contamos com o auxílio de materiais diversos para contextualizar as aulas como: tipos diferentes de rochas, um pequeno exemplar de carvão mineral, um pequeno exemplar de meteorito, aparelho de uso manual com bússola, termômetro e barômetro, binóculos, exemplares de amostras de fósseis de animais 
pré-históricos, da mesma forma que foram realizados ensaios fotográficos para que pudéssemos registrar os momentos da prática realizada.

Angelim é um município do interior de Pernambuco que possui 11.072 habitantes de acordo com o Instituto Brasileiro de Geografia e Estatística - IBGE (2018), localizado no agreste do estado, na microrregião da cidade de Garanhuns, a $216 \mathrm{~km}$ de distância de Recife capital de Pernambuco, tendo como vias de acesso principais as rodovias PE-177 e 187, e tem Quatro Bocas como principal povoado.

\section{Figura 2 - Localização de Angelim e do Povoado Quatro Bocas}

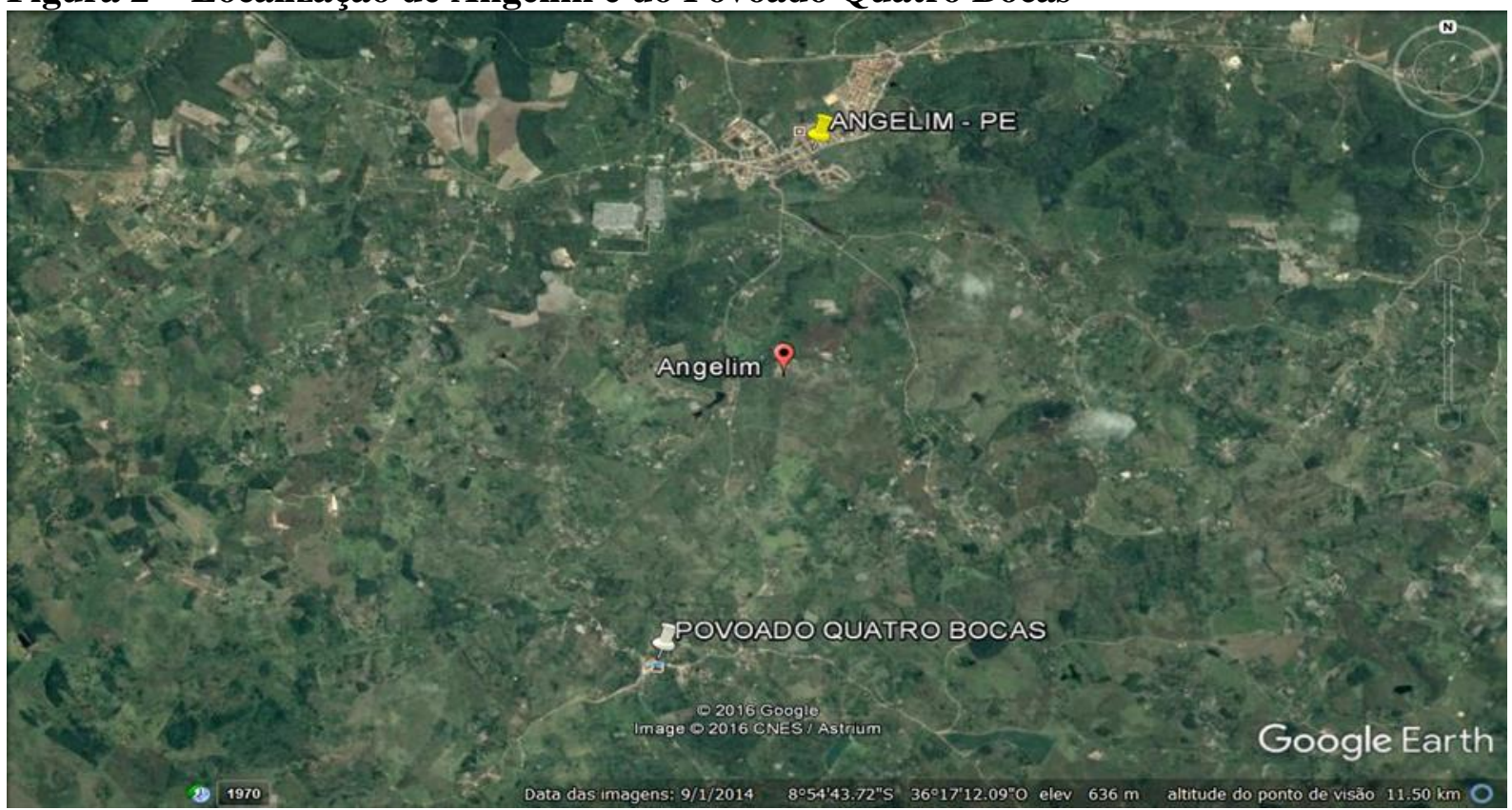

Fonte: Google Earth, Google. Acessado em 09/04/2019

O marcador amarelo mostra a área urbana da cidade Angelim, o vermelho a área rural do município e o branco indica a localização do povoado Quatro Bocas, destino escolhido para a realização das aulas de campo, tendo em vista que é um espaço com boas condições 


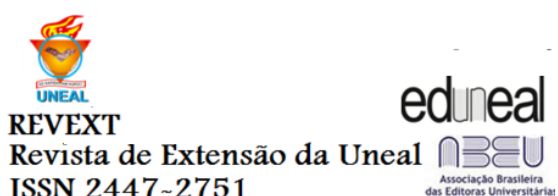

ISSN 2447 2751

Vol. 4, n 1. 2019, Julho de 2019.

para se transitar a pé em segurança com os alunos em seus arredores, assim como, de belas paisagens naturais. O trajeto com as turmas de $6^{\circ}$ ano $\mathrm{A}, \mathrm{B}$ e $\mathrm{D}$, foi realizado através de um ônibus cedido pela prefeitura, entre a cidade de Angelim e o povoado de Quatro Bocas, de lá fizemos um percurso a pé ao redor do povoado por sítios vizinhos, onde pudemos explanar conteúdos e termos a oportunidade de contato direto com o solo, o relevo, a vegetação, aspectos do clima e etc.

Figura 3 - Turmas dos $6^{\circ}$ s anos "a" e "a" na aula de campo

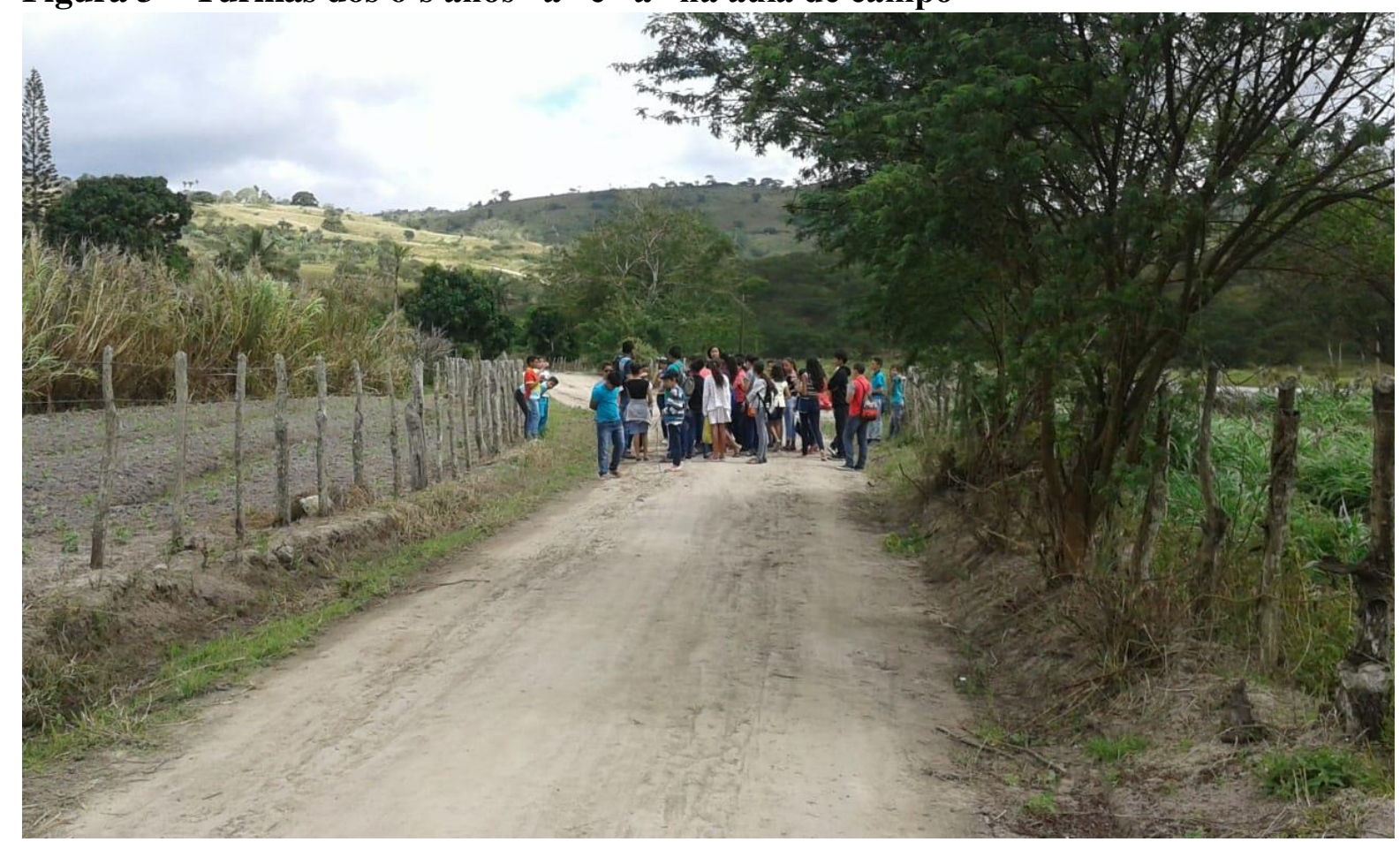

Fonte: Arquivo do autor.

\section{Figura 4 - Turma do $6^{\circ}$ ano "d" na aula de campo}

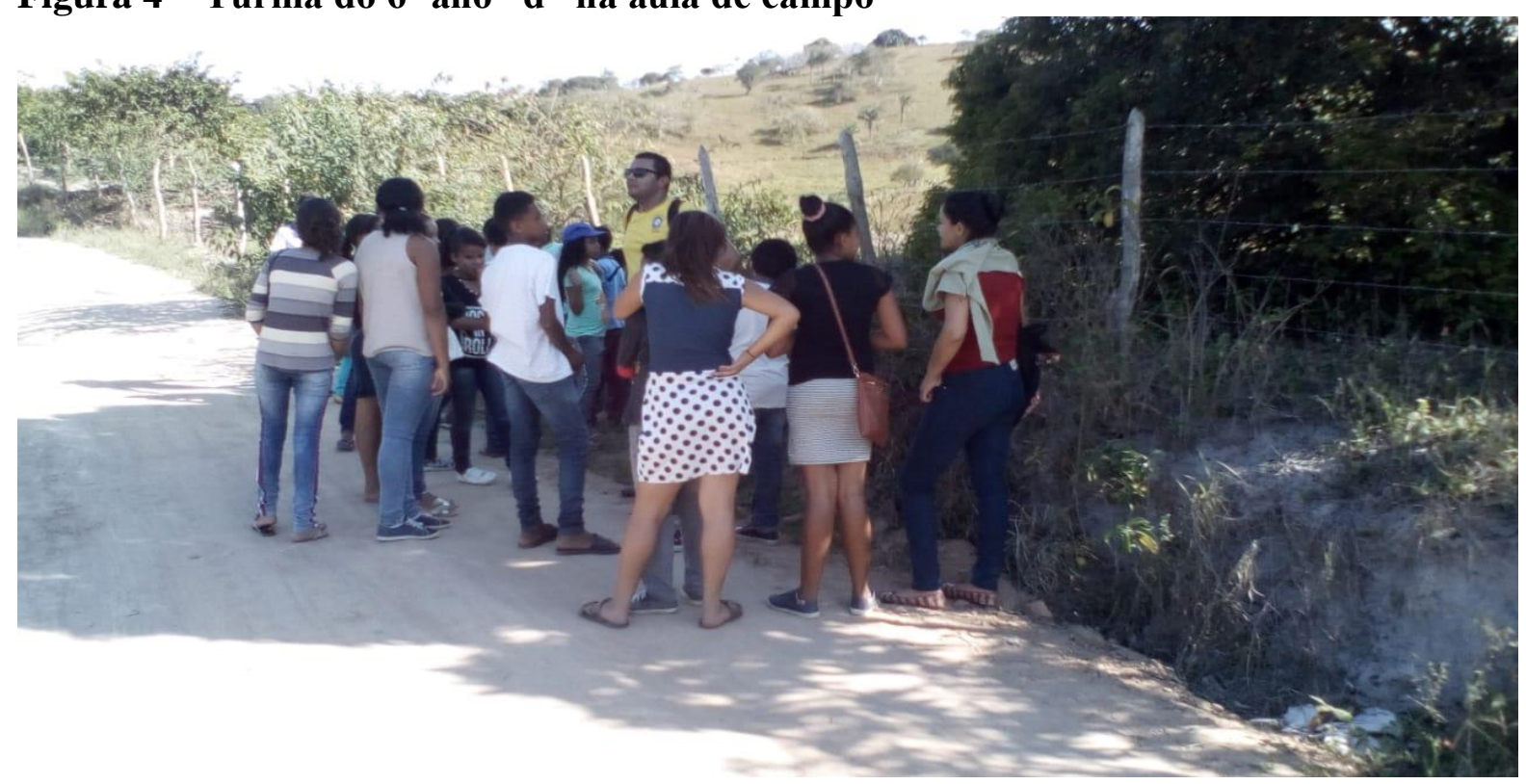

Fonte: Arquivo do autor. 
Da mesma maneira, em momento e oportunidade posterior às aulas de campo, a plicamos uma atividade em sala de aula, com a proposta de avaliar o aprendizado dos mesmos a respeito das temáticas abordadas na aula de campo, já que as aulas de campo procuraram tratar de temas gerais de abordagem geográfica como o relevo, solo, clima, vegetação e o conhecimento prático do espaço geográfico. Solicitamos então, que cada aluno elaborasse um texto com os relatos e aprendizagens adquiridas a partir da aula de campo.

Percebemos que para os alunos a aula de campo realizada foi muito bem aceita, tendo em vista que os discentes em quase sua totalidade gostaram da atividade realizada, a partir de seus depoimentos e comentários.

\section{Resultados}

A educação constantemente necessita de mudanças e práticas pedagógicas diferenciadas, no ensino a dinamicidade é proporcionada pelas novas didáticas que vem mostrando uma nova estrutura nos conceitos educacionais, proporcionando assim um presente ativo e perspectivas de um futuro melhor para a educação, a parir da aplicação dos novos métodos, técnicas e instrumentos que estão à disposição do professor na atualidade.

As inovações na prática docente tendem a alterar padrões tradicionais que ainda persistem na sala de aula, onde muitas vezes o docente apenas impõe práticas em muitos casos ultrapassadas e espera bons resultados, mas sem dar margem à autonomia do discente, onde em diversos casos é negado o seu direito de atuar em seu espaço escolar, desta forma, as aulas de campo promovem uma maior dinamicidade e quebra de rotinas pedagógicas, aproximando o discente dos conteúdos, propiciando aprendizado e melhorando a relação professor-aluno.

Quando práticas didáticas tradicionais sobressaem-se às novas, estamos criando um ambiente de acomodação dos alunos, o que provavelmente acarreta problemas à sua vida escolar e em sociedade, tendo em vista que dessa forma, o aluno deixa de se tornar sujeito e autor de sua formação. As aulas de campo são ferramentas que contribuem para um ensino de qualidade e mostram-se um meio para a emancipação dos alunos, formando assim, cidadãos conscientes e críticos de sua realidade, se forem dirigidas com objetivos claramente definidos para este fim.

Podemos concluir com este estudo que a aplicação adequada das aulas de campo na disciplina Geografia traz diversos benefícios ao ensino e também à aprendizagem dos alunos, principalmente quando uma gama de elementos e fatores são integrados ao seu contexto, colaborando assim de forma sistemática para que o conjunto escolar e educacional alcance de maneira plena seus objetivos.

Da mesma forma que percebemos que há benefícios específicos e resultados positivos à disciplina Geografia, já que tal recurso enriquece o ensino da disciplina e leva os educandos a entenderem o mundo à sua volta, assim como a entender o espaço geográfico de forma mais criativa e dinâmica, contribuindo deste modo para a formação de cidadãos geograficamente críticos, fazendo com que a Geografia atinja seus objetivos como disciplina escolar.

A prática de campo realizada com as turmas de $6^{\circ}$ s anos A, B e D da escola Miguel Calado Borba surtiu efeitos positivos, tanto quando nos referimos à dinamicidade das aulas, assim como à melhoria da aprendizagem dos alunos, tem em vista que a motivação, a participação e o entusiasmo dos mesmos mediante a realização das aulas de campo foi bastante satisfatório, já que a partir da elaboração do texto/relatório a respeito da aula de campo, percebemos que os alunos aprenderam de forma mais efetiva os conteúdos abordados na aula e conseguiram relacioná-los com outros conteúdos abordados em sala anteriormente, 
levando também em consideração os seus questionamentos e comentários no decorrer da aula de campo e posteriormente.

Mediante a análise que realizamos com esta prática pedagógica concluímos que as aulas de campo são ferramentas muito significativas a serem utilizadas no ensino de geografia, já que existe uma gama de conteúdos que podem ser abordados e utilizados em sua realização, além de diversas metodologias podem ser associadas à sua realização, assim sendo, tal ferramenta é muito importante e torna-se imprescindível para o ensino da disciplina Geografia em todas as suas formas.

Não estamos aqui afirmando que as aulas de campo são a salvação das metodologias atuais da disciplina Geografia, e sim que elas podem contribuir para a dinamização das práticas docentes e ao mesmo tempo colaboram para o aprendizado discente, assim como, para a mudança que queremos na sociedade, já que as mesmas fornecem subsídios para a formação de cidadãos mais atuantes em seu espaço cotidiano.

\section{Discussões}

Há tempos o mundo vem vivenciando uma gama de mudanças jamais vistas na história da humanidade, esse momento de rupturas de paradigmas trouxe consigo reflexos em todos os campos da sociedade, sendo a educação uma das áreas que mais vem sofrendo transformações no mundo globalizado, assim como Carlos (1997, p. 63) diz que "Essas mudanças são hoje cada vez mais rápidas e profundas, gerando novas formas de configuração espacial, novo ritmo de vida, novo relacionamento entre as pessoas, novos valores".

As mudanças da sociedade de uma fase industrial para a sociedade do conhecimento determina a formação de profissionais preparados para atuar com os novos processos temporais, pois os instrumentos dos novos tempos favorecem o desenvolvimento de metodologias educacionais que propiciem a busca incessante de aprimoramento com o intuito de promover um aprendizado mais eficaz em sua prática e a interatividade dos discentes com o espaço em que vivem. Nesta perspectiva, Grinspun (2006, p.71) enfatiza: "Inúmeros são os desafios que a escola hoje tem que enfrentar, pois, inúmeros são os desafios da própria sociedade, em ritmo crescente de mudança em todos os seus segmentos".

Em se tratando de desafios, atualmente nos deparamos com uma escola diferente de alguns anos, já que o contexto escolar agora possui um grau de complexidade muito maior, principalmente devido ao perfil dos estudantes na atualidade, onde em diversas situações os valores estão sendo distorcidos e a indisciplina e os conflitos entre aluno/professor são constantes. Assim sendo é necessário um profissional que oriente, auxilie e promova aulas mais dinâmicas que prendam a atenção dos alunos, principalmente quando favorecem a relação do ser com seu ambiente de vivência, ou seja, o espaço geográfico. Um dos objetivos das aulas de campo na atualidade é também proporcionar ao aluno o conhecimento pessoal e da realidade sociocultural onde ele encontra-se inserido. Assim sendo, as aulas de campo surgem como instrumento de suporte ao ensino da Geografia. Silva, et al (2010, p.192) corrobora da seguinte forma "O trabalho de campo estimula de tal forma a curiosidade do aluno que a vivência do que se estuda se torna clara e a teoria começa a ganhar um valor impensável pelos alunos, além de estimular a leitura, o aprofundamento, e o questionamento. Conforme Pisetta (2013):

Importante elemento para o desenvolvimento do processo de ensino aprendizagem, o trabalho de campo permite ao aluno compreender aspectos de realidades complexas a partir de elementos empíricos, além de dinamizar o trabalho do professor e viabilizar uma articulação teórico-prática entre os 
Vol. 4, nº 1. 2019, Julho de 2019.

conteúdos trabalhados em sala de aula e as observações sobre o lugar visitado. (PISETTA, 2013, p. 5).

Esse contato do aluno com o espaço de vivência revela elementos que contribuem para o ensino aprendizagem, aliando a teoria com a prática, dinamizando assim o trabalho docente, auxiliando desta forma para o bom andamento do trabalho escolar e consequentemente da relação professor-aluno.

A aula de campo é uma ferramenta didática que contribui na superação de desafios, pois além de aproximar a teoria da realidade, vincula a leitura e a observação, situações e ações que, associadas à problematização e à contextualização encaminhadas pelo docente, ampliam a construção do conhecimento pelo aluno. Essas possibilidades permitem ao discente experimentar e desenvolver outras inteligências que nem sempre são contempladas e incentivadas na sala de aula. (ZORATTO e HORNES, 2014). Ainda de acordo com Zoratto e Hornes (2014):

É perceptível que a Aula de Campo favorece maior proximidade entre alunos e educador, isso se viabilizando através de conversas durante a caminhada, relatos sobre observações, curiosidades por parte dos alunos, intervenções realizadas pelo docente. $\mathrm{O}$ ambiente distinto da sala de aula também contribui para a superação de estereótipos entre os envolvidos, pois é possível que os alunos consigam perceber um professor mais acessível, humano, assim como alunos melhor se revelarem ao grupo; por vezes alunos introvertidos ou mais resistentes a participar da aula se apresentam mais leves, abertos ao diálogo, e o professor encontra aí uma oportunidade de se aproximar, criar algum vínculo, uma via de comunicação embasada no respeito e na confiança, via que poderá depois se fortalecer em sala de aula. (ZORATTO e HORNES, 2014, p. 8).

Assim sendo, as aulas de campo são ferramentas importantes para relação professor/aluno e também para envolver os alunos na construção de uma aprendizagem significativa que realmente faça a diferença nas suas vidas, tendo em vista que torna-se um momento que marca a vida escolar do aluno, instigando desta forma, seu interesse pelo aprendizado. De acordo com Fontinha (2017):

A relação da Geografia com a observação direta remonta à sua origem. Desde cedo, o trabalho de campo foi considerado uma metodologia essencial no estudo da Geografia, na sua dupla vertente: científica e pedagógica. Contudo, ao longo do tempo, a adoção de Saídas de Campo não foi, um processo linear nem imediato. (FONTINHA, 2017, p. 1).

A pertinência da análise das saídas de campo no seio da Geografia escolar, prende-se com o facto de estas terem uma metodologia específica, quer na sua vertente científica, quer na pedagógica, podendo ser valorizadas como experiências didático-pedagógicas eficazes em atividades curriculares ou extracurriculares. As saídas de campo não sendo, propriamente, uma metodologia nova, podem ser inovadoras e atuais, acompanhando a evolução dos paradigmas científicos e pedagógicos. Assim, questionamo-nos sobre a evolução e a importância atribuída a esta metodologia até aos dias de hoje, considerando que o desenvolvimento das mesmas é prioritário para a formação/educação geográfica e o aumento do sucesso escolar na disciplina de Geografia. (FONTINHA, 2017).

As aulas de campo são ferramentas pedagógicas muito versáteis, já que podem agregar várias metodologias, técnicas e procedimentos educacionais, proporcionando a integração da 
didática de sala de aula com o trabalho prático, facilitando assim por parte do estudante a apreensão de conhecimentos que o levarão a construir uma personalidade mais ativa em relação ao seu espaço de vivência, do mesmo modo que contribui para o discente compreender de forma mais prazerosa as inter-relações que compõem o espaço geográfico.

A Geografia, redefinida enquanto ciência social deve proporcionar aos estudantes elementos e competências para que eles possam refletir e ser transformadores de seus próprios espaços, e para isso, ela deve fornecer elementos básicos a fim de gerar "consciência geográfica", fazendo com que o aluno se perceba e perceba sua relação com a sociedade, se (re) insira no espaço, no seu próprio espaço (JÚNIOR E GONÇALVES, 2012). Ainda conforme Júnior e Gonçalves (2012):

Nesse contexto, a aula de campo pode oportunizar a compreensão da leitura do mundo, uma vez que a Geografia pode contribuir para uma "contraocultação do aparente", isto é, a Geografia deve oportunizar a compreensão do espaço geográfico que, por sua vez, é muito mais que um conjunto de objetos que a percepção sensorial humana pode identificar, pois o espaço geográfico é fruto da interdependente relação entre a sociedade e a natureza, um bilicalmente relacionado à natureza e a sua exploração, bem como é uma construção social, um produto histórico - construído socialmente, por meio do trabalho, sendo assim, um produto-processo da necessidade ontológica da existência do homem. Além disso, o espaço é influenciado pela dinâmica das ações (antrópicas, químicas ou físicas), é onde os fenômenos incorporam-se, portanto, a geografia pode auxiliar a compreensão daquilo que é o mundo, podendo auxiliar no entendimento daquilo que é além da matéria(lidade). (JÚNIOR e GONÇALVES, 2012, p. 2).

Deste modo, entendemos que as aulas de campo possuem bastante influencia na aprendizagem dos alunos, isso quando nos referimos à relação conteúdo de sala/prática de campo e o professor, sendo assim, essa metodologia utilizada na disciplina Geografia traz benefícios diretos ao que todas as propostas educacionais prezam constantemente, o aprendizado discente. Além de contribuírem para enriquecer o trabalho docente e dinamizar as relações entre professor e aluno que em muitos casos encontra-se tão desgastada e problemática. Segundo Cordeiro e Oliveira (2011):

A aula de campo constitui um importante elemento para desenvolvimento do processo de ensino-aprendizagem, permitindo ir além da simples exposição mecânica dos conteúdos em sala de aula ao possibilitar a compreensão de uma realidade complexa a partir de um dado palpável, além de contribuir para enriquecer a disciplina de Geografia e dinamizar o trabalho do professor (CORDEIRO e OLIVEIRA, 2011, p. 1).

Através do trabalho com abordagens metodológicas inovadoras, aliadas à utilização de diferentes recursos didáticos, o aluno percebe que os conteúdos geográficos podem ser registrados e analisados por diferentes formas de linguagem, inclusive visuais, auditivas ou de tamanho proporcional ao natural. Esse posicionamento faz com que o educando perceba que a Geografia vai além de algumas páginas de um livro, ou de uma sala de aula, mas que a mesma pode ser presenciada em diversos meios que o próprio aluno vivencia em seu cotidiano. (JÚNIOR e OLIVEIRA, 2011).

Desta forma, as aulas de campo são importantes e cumprem um papel significativo para a vida do estudante, para a disciplina Geografia e para o trabalho docente e tem a função de auxiliar para uma educação de qualidade, contribuindo assim para que o contexto escolar 
em todas as suas formas cumpra seus objetivos. Subsidiando a implementação de uma prática pedagógica sistemática que atenda às necessidades dos alunos e, contribua com o processo de ensino-aprendizagem. Tendo assim o poder de abranger o ser humano como um todo, estando ligada diretamente à formação de alunos conscientes de seu papel na sociedade, sendo portanto, uma metodologia compromissada com a formação do aluno, especialmente no que diz respeito aos seus valores, atitudes, emoções e sentimentos.

Sendo a aula de campo, ferramenta metodológica importante para o ensino, esse processo de ensino - aprendizagem é o caminho para o "desenvolvimento" do aluno, não só na escola, mas em toda a sociedade, pois ao conviver com a realidade, e podendo argumentar sobre a mesma, fazendo conexões com o teórico, torna-o um ser crítico, e esse é um dos papeis do ensino da geografia, formar cidadãos críticos. (SILVA e JÚNIOR, 2016).

Deste modo, conseguimos compreender de uma forma mais clara que a as aulas de campo contribuem para além das particularidades da sala de aula, auxiliando na formação de um cidadão consciente e atuante na sociedade, transcendendo assim às paredes da escola, aspirando a uma integração de uma sociedade melhor.

\section{Considerações finais}

O ensino vem se mostrando muito dinâmico ultimamente e toda essa dinamicidade é proporcionada pelas novas ferramentas que vem se mostrando eficientes e convincentes do novo futuro que se mostra no horizonte, inevitavelmente tais mudanças trazem um novo conceito quando se trata da função das aulas de campo.

As aulas de campo é uma ferramenta que veio para contribuir para o aprendizado, formação e integração de todos os alunos no ensino-aprendizagem, também se mostra como uma nova arma para emancipação dos educandos se a sua função for realmente desempenhada como deve, dirigida para os reais objetivos, assim podemos usufruir de melhores resultados nos processos educacionais e consequentemente sociais, contribuindo assim para a construção de uma sociedade mais justa, igualitária e consciente.

Com este estudo, podemos concluir que as aulas de campo trazem contribuições muito visíveis e eficazes para o aprendizado dos alunos, para a educação e a vida dos educandos, principalmente quando uma gama de fatores e ferramentas educacionais e sociais é integrada e colabora em conjunto para que sejam alcançados os resultados esperados.

Da mesma forma, percebemos que há benefícios e resultados positivos exclusivos desta metodologia para a disciplina Geografia, pois ela enriquece bastante o trabalho do educador e leva os estudantes a descobrirem seu espaço de uma forma mais dinâmica e prática, do mesmo modo, que contribui para a formação de cidadãos críticos, participativos, atuantes e conscientes de seu papel no mundo, sendo esse um dos principais objetivos da disciplina Geografia contemporânea.

A partir da pesquisa realizada, foi possível perceber que as aulas de campo surtem efeitos positivos e apresentam resultados imprescindíveis, tanto quando nos referimos à dinamicidade das aulas e a melhoria do desempenho da aprendizagem do alunado, já que os alunos sentem-se mais seguros e firmes de seu papel na sociedade, a partir da influência que as aulas de campo oferecem às suas trajetórias escolares.

Diante da análise que realizamos com esta pesquisa, constatamos que as aulas de campo são muito significativas para a disciplina de Geografia em geral, já que existe uma grande quantidade de possibilidades e oportunidades disponíveis a partir da efetivação desta ferramenta. Não estamos aqui afirmando que as aulas de campo são a redenção da educação contemporânea, mas sim que elas podem contribuir muito para a mudança que queremos na 
realidade da educação, e para que consigamos redescobrir a cada dia e de acordo com os novos tempos o verdadeiro papel da educação para uma sociedade melhor.

Nossos sinceros agradecimentos à FAPEAL / CAPES (Fundação de Amparo à Pesquisa do Estado de Alagoas / Coordenação de Aperfeiçoamento de Pessoal de Nível Superior) pelo apoio financeiro que tais agências de fomento à pesquisa vem nos fornecendo para o desenvolvimento de nossas pesquisas e para o bom andamento de nossas atividades no curso de Mestrado em Geografia da Universidade Federal de Alagoas.

\section{Referências}

CARLOS, Ana Fani A. A cidade. São Paulo: Contexto, 1997.

CORDEIRO, Joel Maciel Pereira. OLIVEIRA, Aldo Gonçalves de. Aula de campo em Geografia e suas contribuições para o processo de ensino-aprendizagem na escola. Revista Geografia (Londrina), v. 20, n 2, p. 099-144, maio/ago.2011.

EARTH, Google. Área urbana e rural do município de Angelim-PE. Disponível em: https://earth.google.com. Acessado em 09/14/2019.

FONTINHA, Filipa. Saídas de Campo no Ensino da Geografia: Uma Metodologia Ainda Atual? Revista de Educação Geográfica|UP, nº.1, p.79-91. (2017). Universidade do Porto.

GRINSPUN, M.P.S. Orientação Educacional: Conflitos de paradigmas e alternativas para a escola. $3^{\text {a }}$ ed. São Paulo: Cortez, 2006.

JÚNIOR, Francisco de Assis do Nascimento. GONÇALVES, Francisco Ednardo. A aula de campo como estratégia pedagógica para a Geografia no Ensino Médio Integrado. VII Connepi, Palmas/TO, 2012.

PISETTA, Neli Alves dos Santos. A importância do trabalho de campo no ensino de Geografia. In: Os desafios da escola pública paranaense na perspectiva do professor: produções didático-pedagógicas. SEED/PR, Curitiba/PR, volume I, 2013.

SILVA, André Felipe da. JÚNIOR, Rogério José de Oliveira. Aula de campo como prática de ensino-aprendizagem: sua importância para o ensino de Geografia. XVIII ENG, São Luís/MA, 2016.

SILVA, Juliana Santana Ribeiro da. SILVA, Míriam Belarmino da. VAREJÃO, José Leonídio. Os (des)caminhos da educação: a importância do trabalho de campo na geografia. VÉRTICES, Campos dos Goytacazes/RJ, v. 12, n. 3, p. 187-197, set./dez. 2010.

ZORATTO, Fabiana Martins Martin. HORNES, Karin Linete. Aula de campo como instrument didático-pedagógico para o ensino de Geografia. In: Os desafios da escola pública paranaense na perspectiva do professor: produções didático-pedagógiccas. SEED/PR, Curitiba/PR, volume I, 2014. 